\title{
Espiritualidad compartida en encuentros interreligiosos Cristiano-Budistas
}

\author{
Shared Spirituality in Christian-Buddhist \\ Interreligious Encounters
}

Juan Masiá Clavel SJ

\section{Resumen}

Es posible viviry practicar una espiritualidad cristiano-budista, compartida en encuentros interreligiosos. Esto se confirma en la experiencia de grupos de personas budistas y cristianas que se reúnen para unos ejercicios espirituales interreligiosos, en los que comparten la lectio divina y recitación de "sagradas escrituras", los tiempos fuertes de silencio interior y los ratos de conversación sobre la fe, para animarse mutuamente a la práctica de la misericordia, aprendida del Buda en el Sutra del Loto y de Jesús en el Evangelio. El artículo presenta la crónica de convivencias de encuentros interreligiosos cristianobudistas, ejemplificando la transformación de las respectivas espiritualidades, mediante la convergencia que se produce cuando creyentes de ambas, en clima de lectura, meditación y conversación espirituales, intercambian sus formas respectivas de vivir la fe. A continuación, presenta una lectura del Sutra del Loto, desde la perspectiva de la tradición religiosa propia, que se redescubre y transforma, en el encuentro con la ajena. Concluye con una reflexión sobre el sentido profundo de "lo oriental" en el Buda y en Jesús.

Palavras-chave: Espiritualidad. Encuentros interreligiosos. Diálogo cristianobudista. Diálogo interreligioso. Misericordia.

\section{Abstract}

It is possible to live and to practice a shared Christian-Buddhist spirituality 
in interreligious encounters. This is confirmed in the experience of groups of Buddhists and Christians who come together for interreligious spiritual exercises, in which they share lectio divina and recite from "sacred writings", strong periods of interior silence and moments of conversation about faith, in order to animate each other mutually in the practice of mercy, learning from the Buddha and the Lotus Sutra and from Jesus in the Gospel. The article presents the chronicle of lived experiences from Christian-Buddhist interreligious encounters that exemplify the transformation of the respective spiritualities by means of the convergence that is produced when believers of both traditions, in a climate of reading, meditation and spiritual conversations, interchange their respective forms of living their faith. Following this, a reading from the Lotus Sutra is presented from the perspective of its own religious tradition that is rediscovered and transformed in the encounter with the other. It concludes with a reflection on the profound meaning of "the Eastern Way" in the Buddha and in Jesus.

Keywords: Spirituality. Interreligious encounters. Christian-Buddhist dialogue. Interreligious dialogue. Mercy.

\section{Introducción}

¿Es posible vivir y practicar una espiritualidad cristiano-budista, compartida en encuentros interreligiosos? La respuesta afirmativa a esta pregunta se confirma en la experiencia de grupos de personas budistas (B) y cristianas (C) que se reúnen para unos ejercicios espirituales interreligiosos (EEI), en los que comparten la lectio divina y recitación de "sagradas escrituras", los tiempos fuertes de silencio interior y los ratos de conversación sobre la fe, para animarse mutuamente a la práctica de la misericordia, aprendida del Buda en el Sutra del Loto y de Jesús en el Evangelio.

Teniendo como telón de fondo la práctica de estos EEI, propondré una lectura del Sutra del Loto con perspectiva interreligiosa.

Resumiré brevemente la crónica de dichas convivencias EEI, convivencias en las que tuve personalmente la participación, ejemplificando la transformación de las respectivas espiritualidades, mediante la convergencia que se produce cuando creyentes de ambas, en clima de lectura, meditación y conversación espirituales, intercambian sus formas respectivas de vivir la fe. A continuación, expondré una lectura del Sutra del Loto, desde la perspectiva de 
la tradición religiosa propia, que se redescubre y transforma, en el encuentro con la ajena. Concluiré con una reflexión sobre el sentido profundo de "lo oriental" en el Buda y en Jesús.

Solamente una advertencia preliminar. La experiencia presupuesta en estas reflexiones no es la de un diálogo de estudio comparativo sobre budismo y cristianismo, sino la de unos encuentros de espiritualidad. Personas creyentes de ambas religiones descubren la posibilidad de una convergencia de espiritualidades; comparten sus modos respectivos de meditar, conversar y practicar la fe que anima los textos sagrados de su religión: la luz sapiencial del satori (despertar) en el Loto y la vida de agape (amor-gracia) en el Evangelio. Por eso, a dicha convivencia interreligiosa la llamo intencionadamente encuentro, para subrayar el carácter de encuentro espiritual entre miembros de religiones diferentes que convergen por el camino de las prácticas de meditación y compasión. No se trata de diálogos comparativos entre budismo y cristianismo mediante el intercambio, en un marco académico, de estudios históricos, exegéticos y doctrinales; tampoco se trata de un diálogo institucional entre dos religiones. Estas otras dos clases de diálogos interreligiosos son, por supuesto, muy importantes y necesarios; en realidad, la mayoría de las personas participantes en los encuentros aquí referidos, participaron también, como miembros de la WCRP o de la ACRP, ${ }^{1}$ en esos diálogos interreligiosos institucionales, culturales o académicos. De hecho, algunas se conocieron en ese contexto y surgió la propuesta de reunirse en pequeña comunidad para unos retiros de meditación y convivencia interreligiosa.

\section{Ejercicios de espiritualidad interreligiosa (EEI) cristiano- budista}

El esquema de una sesión en un día de retiro espiritual interreligioso es el siguiente:

A) Lectura espiritual. Introducciones a la lectura en común de dos textos religiosos: uno, de los Evangelios; otro, del Sutra del Loto. Las personas facilitadoras encargadas de hacer las introducciones a la lectura espiritual, las exponen brevemente durante 15 minutos.

B) Recitación salmódica. El grupo pasa de la sala de reunión al oratorio para recitar allí en coro, pausada y rítmicamente los dos textos. En

\footnotetext{
${ }^{1}$ WCRP: World Conference of Religions for Peace. ACRP: Asian Conference of Religions for Peace.
} 
una sesión dedicada al tema del perdón y reconciliación estos textos fueron los siguientes:

- Una selección del Evangelio según Lucas: 6, 27-36 “Bendecid a los que os maldicen, orad por los que os persiguen".

- Una selección del capítulo 20 del Sutra del Loto: el "bodisatva despreciado que a nadie menospreció"; bendecía a los que le maltrataban, les sonreía profetizándoles que también ellos alcanzarían la iluminación y diciéndoles: "Todos os convertiréis en Budas".

C) Silencio interior. Todo el grupo, incluidas las personas moderadoras de la conversación o facilitadoras de la lectura, pasa media hora de silencio interior, ya sea arrodillados en postura de loto, practicando zazen, o sentados correctamente, o paseando despacio, según sea apropiado para cada persona corporal o anímicamente.

D) Conversación. Tras una breve interrupción de descanso, el grupo se reúne en círculo de conversación para compartir fe y vida.

Del diario de las sesiones del grupo de EEI, extraigo unos fragmentos de conversaciones tras la lectio divina interreligiosa del Loto y el Evangelio. Son solo pequeñas muestras de vivencias de espiritualidad compartida.

\subsection{Parábolas y upayas performativos}

La lectura de la parábola de la casa incendiada, en el capítulo 3 del Sutra del Loto, y de la parábola del buen samaritano, seguida de la visita de Jesús a casa de Marta y María, (Lc 10, 25, 42), suscitó ecos budistas (B) y cristianos (C), como en el extracto siguiente:

B. "Solamente una cosa es necesaria". He escuchado esta palabra como si me la dijera un maestro de meditación Zen, provocándome a descifrar una paradoja o "kôan". Lo mismo que el final de la parábola evangélica: "Ve y haz tú lo mismo, hazte prójimo".

C. Es cierto, las parábolas nos descolocan. Jesús concluía diciendo: "Quien pueda entender que entienda". Con palabras parecidas nos reprende el maestro del Zen cuando intentamos explicar quién es el prójimo o por qué la estratagema de prometer juguetes diferentes a los niños para sacarlos de la casa en llamas. 
B. Ambas parábolas son "upaya" o recursos de que se vale Jesús o el Buda, hablándole a cada persona de manera que le ayude a descubrir en su interior lo "único necesario" o el "vehículo único". Los historiadores discuten sobre los diferentes vehículos o caminos hacia la Verdad. Pero el Buda quiere que caigamos en la cuenta de que el único camino está en nuestro interior.

C. Y yo tendré que agradecerle al Buda que me hace caer en la cuenta de lo que quería decir Jesús, mejor dicho, de lo que quería hacer conmigo al confrontarme con la parábola; esta era un "upaya", un "recurso de salvación". ; Tantos años oyendo la parábola de Jesús y no me había dejado cambiar por ella!

\subsection{Por la parábola a la mística}

La lectura de las parábolas evangélicas sobre el tesoro escondido (Mt 13, 44-46) y la parábola budista de la perla regalada e ignorada (Loto, cap. 8), suscitó ecos budistas (B) y cristianos (C), como en el extracto siguiente:

B. "Mientras el huésped dormía, su amigo generoso le dejó una perla preciosa como regalo de despedida. Al cabo de los años, se encuentran casualmente y el amigo se sorprende ante el aspecto miserable del otro. Mientras dormías, le dice, te dejé cosida en el dobladillo del cuello de tu capa una joya valiosa. Por no darte cuenta, has pasado penalidades". Cuando recito y medito esta parábola, me conmueven las palabras del discípulo: "El Buda es como aquel amigo. Nos ha enseñado que cada persona abriga en su interior un tesoro inapreciable: la iluminabilidad. Por eso podemos, mediante la práctica del Camino, alcanzar la iluminación".

C. Ha dicho usted "iluminabilidad" e "iluminación". Me alegro de que lo exprese con esas palabras; me ayudarán cuando hable en mi idioma sobre budismo, para explicarlo a personas que están más familiarizadas con el Evangelio que con el Loto. Les resultará más difícil de entender, si les hablamos de "naturaleza búdica" o de "alcanzar la budeidad y hacerse Buda".

B. Es tradicional decirlo con la imagen luminosa: "luz de tu interior, luz del Dharma". Aprendimos del Buda que todos los seres tienen esa luz, pero los humanos son además capaces de darse cuenta y hacerse iluminados. Eso es lo que significa hacerse Buda: hacerte lo que eres, dándote cuenta de lo que eres, de tu luz interior.

C. En ese caso, yendo más lejos, ¿le parece a usted bien que, al hablar a un 
público cristiano sobre la naturaleza búdica, me refiera a esa luz interior aludiendo a la presencia divina del Espíritu de Vida dentro de mí?

B. Sí, muy bien. Pero usted no podría decir que Dios está dentro de usted, si no fuera porque ya desde siempre usted está dentro de Él y envuelto por Él.

C: Así es, y así lo recitamos en el salmo 138: "Me estrechas detrás y delante, me cubres con la palma de tu mano". Y los versos que tanto gustaban a la mística Teresa de Ávila dicen así: "Alma, buscarme has en tí, buscarte has en mí".

B. Entonces el Dios personal cristiano no es tan opuesto al Buda eterno de la iluminación original, como a veces se dice...

C. Pero no será fácil concordar a budólogos y teólogos. A no ser que, antes de sentarse a la mesa redonda del debate, se sienten a respirar y meditar para percatarse de la "luz interior, luz del Dharma"...

\subsection{Parábolas de misericordia}

La lectura del ejemplo del bodisatva Jamás-Menosprecia, en el capítulo 20 del Loto, acompañada por el mensaje de perdón y amor a los enemigos en el Evangelio (Lucas 6, 27-36), suscitó ecos budistas (B) y cristianos (C), como en el extracto siguiente:

C. Para mí, esta historia del bodisatva humilde que practica la compasión, despreciado por los monjes orgullosos y teóricos del budismo que no practicaban la compasión, sino se burlaban de él y lo maltrataban, me llega mucho al corazón. Cuanto más le menospreciaban, más les sonreía diciendo: "Estáis llamados a ser Budas". Este bodisatva estaba bendiciendo a los que lo perseguían y orando por los que lo maldecían, como dice el Evangelio (Mt 5, 44 y Lc 6, 28).

B. Sí, es uno de los temas de mayor coincidencia.

C. Y también de mayor dificultad. Al día siguiente del ataque terrorista, les costaba trabajo a las personas cristianas hablar de justicia reconciliadora en vez de vengativa.

B. Pero estará usted de acuerdo en reconocer que nosotros mismos estábamos de algún modo entre los terroristas que estrellaron su avión contra las torres gemelas...

C. ¿Cómo dice?

B. Usted y yo nos sentimos, sin duda, aquel día víctima con las víctimas. La solidaridad humana nos hace sentir que en cada persona asesinada muere 
una parte de uno mismo. Pero también usted y yo podemos reconocer que tenemos raíces de violencia en nuestro interior. Por ahí conectamos con las raíces del mal de los agresores. Todos llevamos dentro raíces y semillas de paz y de violencia; si no cultivamos las de paz y no desarraigamos las de violencia, todos albergamos dentro un posible terrorista. Creo que esto diría el Buda. Supongo que Jesús diría lo mismo.

C. Me está usted redescubriendo la parábola del trigo y la cizaña.

B. Así es como nos ayudamos mutuamente en estos encuentros a redescubrir lo que ya teníamos o a darnos cuenta de que hay que practicarlo como camino para descubrirlo; es simplemente el camino del bodisatva...

C. El Camino, podemos decir con Jesús, de quien nos enseñó la Verdad de la Vida...

Hasta aquí los extractos de conversaciones en los EEI. Los he seleccionado a propósito coincidiendo con la triple temática central del Sutra del Loto, que voy a recorrer en sus líneas generales, relacionándola con la espiritualidad del Camino, Verdad y Vida de Jesús.

\section{Camino, Verdad y Vida, entre el Loto y el Evangelio}

Reiterando que no estamos haciendo una investigación históricoexegética comparativa de dos religiones, sino una reflexión sobre la experiencia compartida por dos espiritualidades que se transforman mutuamente por el camino hacia la verdad de la vida, veamos ahora tres temas básicos en el Tríptico de los Sutras del Loto. ${ }^{2}$ Si se tratase de introducir al estudio de este texto religioso budista, habría que situarlo primero en el contexto histórico, socio-cultural y religioso en que nació. ${ }^{3}$ Pero aquí se trata de reflexionar sobre temas centrales del Loto, desde la perspectiva del encuentro interreligioso de espiritualidades que buscan, al compartirse, integrar sus convergencias y

\footnotetext{
${ }^{2}$ MASIÁ CLAVEL, J. (trad. y ed. y en colaboración con Ikuko Tani, Kouchiró Yoshida y Emilio Masiá). El Sutra del Loto. Salamanca: ed. Sígueme, 2009, contiene el Tríptico de los Sutras del Loto con tiene: El Sutra de los Sentidos Innumerables, El Sutra de la Flor del Loto del Dharma Sublime, El Sutra de la Práctica Ascética para contemplar al Bodisatva Sabiduría Consumada. (Cito en adelante esta edición con la abreviatura Loto).

${ }^{3}$ El texto del Sutra del Loto, conocido por la traducción literal de su título como el Sutra de la Flor del Loto del Dharma Sublime (skt. Saddharma-pundarika), se sitúa al final de una trayectoria compleja en la historia del budismo; convergen en él diversas tendencias anteriores. Se trata de uno de los textos más importantes dentro de la corriente Mahayana, redactado primero en sánscrito en el siglo I a.C. y, posteriormente, en chino, en el año 286 de nuestra era.
} 
divergencias para transformarse y ayudarse mutuamente a crecer, tanto en el modo de vivir la fe como en el de expresarla.

Para la lectura interreligiosa del Sutra, nos sirven de hilo conductor tres palabras evangélicas: Verdad, Vida y Camino; pueden coincidir con el triple mensaje que se despliega a lo largo del Tríptico de los Sutras del Loto: 1) el Vehículo Único hacia la Verdad-Dharma, 2) la Vida eterna del Buda Originario y 3) el Camino de la Práctica Compasiva de los Bodisatvas. En primer lugar, en el Sutra del Loto, el Buda emplea como recursos salvificos diversos modos de exponer la enseñanza, sin absolutizar ninguno de ellos; el Buda proclama lo que llama el Vehículo único, más allá de las diversas versiones religiosas que expresan la búsqueda del Camino. La meta del Camino es descubrir y realizar la unión con la Vida eterna del Buda Originario. Finalmente, el Buda desenmascara, a través de la práctica misericordiosa de los bodisatvas, el engaño y la contradicción interna de quienes bajo apariencia de religiosidad traicionan, mediante la violencia, la opción incondicional por la no-agresividad pacífica y pacificadora

Estos tres puntos de énfasis tienen mucho en común con otras tradiciones religiosas diferentes en sus expresiones. Al mismo tiempo, plantean tres retos serios a estas otras tradiciones, a saber: 1) La relativización del lenguaje religioso. 2) El reconocimiento, bajo la pluralidad de expresiones, de la Única Verdad última. 3) La autocrítica de las contradicciones internas intrarreligiosas cuando las religiones con tradición de paz caen en condescender con la violencia.

Recorramos, aunque solo sea a vista de pájaro, estos tres temas a lo largo del Sutra del Loto. ${ }^{4}$

\section{Un Vehículo único hacia la Verdad-Dharma}

El primer sutra del tríptico, que sirve de obertura al Sutra del Loto, es el Sutra de los sentidos innumerables. La puesta en escena es la de un sermón de despedida antes de entrar el Buda Shakamuni en el nirvana definitivo por la puerta de su extinción y muerte. Como indica el título mismo, los sentidos de

\footnotetext{
${ }^{4}$ Corresponden igualmente estos tres temas a la triple expresividad de los dibujos Mandala (con la variedad relativizada y unificada de su imaginario plural), las fórmulas jaculatorias Mantra (con el sentido concentrado en el misticismo de la palabra), y los gestos de manos Mudra (para expresar actitud meditativa, acogida benévola, liberacion exorcizante del mal o compasion universal).
} 
su enseñanza son innumerables, porque el aspecto auténtico de la realidad es inagotable. Hay un fondo único de verdad última, que se expresa en infinidad de manifestaciones.

\begin{abstract}
...La naturaleza del agua es una, mientras que ríos y arroyos, pozos y estanques, torrentes y canales, y el océano mismo son, cada uno, distintos y diferentes... Mi predicación del comienzo, del medio y del presente es una en su letra y su expresión, mientras que los sentidos son diferentes... Solo un Buda puede, junto con otro Buda, escrutarlo completamente... ${ }^{5}$
\end{abstract}

Los discípulos del Buda (DB) heredaron esta enseñanza y expresaron durante siglos su confianza en las "tres joyas" de su tradición religiosa. Siempre repiten, antes de recitar el Sutra, la jaculatoria fundamental: "Me refugio y abandono en manos del Buda, de su Enseñanza y su Comunidad". Los discípulos de Jesús (DJ), que recordaban al que "amó a los suyos hasta el final" (Jn 13, 1), estaban convencidos de que eran incalculables los hechos y dichos del Maestro: "si se escribiesen uno por uno, no cabrían los libros en el mundo" (Jn 21, 25); pero eran bien conscientes de que todo se reduce en el fondo a la Verdad única del Camino de Amor que da Vida (Jn 15, 9-11).

El Buda emplea, como recursos salvificos, diversos modos de exponer la enseñanza, sin absolutizar ninguno de ellos; proclama el Vehículo único, más allá de las diversas corrientes religiosas que expresan la búsqueda del Camino hacia la manifestación del Dharma o Verdad Última de la Vida. La predicación del Loto pretende desvelar el secreto último de la vida, que viene de la vida eterna del Buda Originario y retorna a ella, mediante la práctica de la convivencia benevolente y la misericordia liberadora y compasiva.

Se repite este tema a lo largo de los 14 primeros capítulos y se destaca la búsqueda de la Verdad (con mayúscula) más allá de las verdades (con minúsculas). Se distinguen y relativizan los caminos hacia la verdad y los vehículos con que se los recorre hasta encontrar el Vehículo único que circula por el Camino de la compasión hacia la meta de la Verdad última de la Vida verdadera.

Los "recursos salvíficos" o "estratagemas hábiles" (en sánscrito upaya, y en japonés, hôben) de la predicación del Buda constituyen una relativización notable del lenguaje religioso. El "vehículo único" (ichijô, en japonés; ekayana, en sánscrito) a través de la pluralidad de manifestaciones, es expresión

${ }^{5}$ Loto, pp. 31-34. 
de la unidad de la realidad última manifestada a través del pluralismo religioso. El Buda se manifiesta de diversas maneras y utiliza diversos lenguajes, que pueden y deben ser relativizados. Para salvar a todo el mundo, habla en cada momento y lugar el lenguaje asequible al auditorio. Pero todos los lenguajes y vehículos son hábiles recursos, estratagemas salvíficas. El núcleo de la enseñanza es sublime y difícil: "Sólo un Buda la comprende si se la comunica otro Buda". ${ }^{6}$ Solo quien ha descubierto la luz en el proprio interior la sugiere sin palabras, para que pueda asentir sin palabras quien ha descubierto esa misma luz dentro de sí. A la comunidad DJ le recuerda este pasaje una palabra enigmática del Maestro: "Nadie viene a mi, si el Padre no le atrae" (cf. Jn 6, 66 y Jn 14, 6). El bodisatva Manjusri interpreta para la comunidad CB el enigma del rayo de luz que irradia desde la frente del Buda para iluminar millares de mundos y millones de seres:

Las señales de hoy son como los auspicios de ayer,

Son recursos salvíficos de iluminación.

Ahora el Buda emite una luz cegadora

Que ayuda a desvelar

El verdadero aspecto de la realidad.

Que aprendiéndolo los humanos

Lo reciban de todo corazón, con las manos juntas

El Buda hará que caiga la lluvia del Dharma

Y colmará a los que buscan el Camino.

$\mathrm{Si}$, entre aquellos que buscan los tres vehículos

Alguno abrigare dudas o pesares

El Buda ciertamente los disipará

Eliminándolos sin rastro alguno. ${ }^{7}$

Pero esta verdad no es monopolio elitista de un grupo; es para todo el mundo. Por eso el Buda eterno recurre a infinidad de recursos o estratagemas de salvación: la diversidad de vehículos de la enseñanza: "Valiéndome de innumerables recursos salvíficos he guiado a los seres vivientes para que se desliguen de los apegos". ${ }^{8}$ Se muestra en las siete parábolas típicas del Loto, sobre todo, en la citada antes de la casa incendiada y la evacuación de los niños en peligro, que reciben al salir el premio de un regalo único espléndido.

\footnotetext{
${ }^{6}$ Loto, cap. 2, p. 72.

${ }^{7}$ Loto, cap. 1, p. 70.

${ }^{8}$ Loto, cap. 2, p. 71
} 
Hábilmente me valí de estratagemas

Les hablé de tres vehículos

Que conducen a la salvación y libran

A todos los seres de las angustias...

Para bien de todos los seres

Mediante esta parábola proclamo

El único vehículo del Buda.

Si sois capaces de escucharme con fe,

Conseguiréis entrar

En el Camino de la iluminación. ${ }^{9}$

En la época de elaboración de este Sutra en la India, como también en la de su difusión en China y posteriormente en Japón, había una preocupación por integrar y unificar diversas ramificaciones del árbol de la tradición budista. Por eso se presta a una lectura en contexto interreligioso. Así, por ejemplo, se evoca la trayectoria de espiritualidad de los sravakas (principiantes, discípulos a la escucha de la predicación del Buda), los pratyekabuddhas (ascetas aspirantes a la iluminación por sí mismos y para sí mismos) y los bodisatvas (caminantes por el sendero de la práctica virtuosa, que viven para los demás, guiándolos hacia la sabiduría cordial mediante la compasión iluminada).

Para quienes aspiran al estado de sravaka, él predicaba el Dharma adaptado según las cuatro verdades, que salva del nacimiento. De la vejez, de la enfermedad y de la muerte, y conduce a la cima y consumación del nirvana.

Para quienes aspiraban al estado de pratyekabuddha, él predicaba la enseñanza adaptándola según las causas y condiciones (de la cadena causal de doce eslabones).

Para los bodisatvas la predicaba según las seis perfecciones, permitiéndoles llegar a la Iluminación perfecta y acceder al conocimiento del Buda en todos sus aspectos. ${ }^{10}$

\section{Vida eterna del Buda Originario}

En un simposio cristiano-budista, que se celebró con motivo de la publicación en español del Sutra del Loto, se propusieron como tema del

\footnotetext{
${ }^{9}$ Loto, cap.3, p. 120.

${ }^{10}$ Loto, cap 1, pp. 61-62.
} 
encuentro al inicio del diálogo, dos sentencias emblemáticas del Loto y el Evangelio:

"Yo estoy con vosotros todos los días hasta el fin de los siglos" (Mt 28, 20).

"Siempre morando con vosotros, predicando el Dharma" (Sutra del Loto, cap. 16). ${ }^{11}$

En la clausura del simposio se resumió la conclusión con las palabras de Jesús sobre el Camino, la Verdad y la Vida, relacionadas con las del Buda Shakamuni: "Quién me ve, está viendo al Dharma". Las comunidades del discipulado cristiano (DJ) y budista (DB), que leen, recitan y meditan paralelamente el Evangelio y el Loto, se refugian y abandonan (namu) en la confianza radical que suscita la escucha de la palabra de Jesús: "Quien me ve, reconoce al Padre" (Jn 14, 9) y la palabra de Shakamuni: "Quien me ve, reconoce al Dharma". ${ }^{12}$

Comienza el diálogo con la exposición por parte de la comunidad DB del capítulo 16, que contiene el tema central del Sutra del Loto. Shakamuni es el Buda, es decir, el iluminado por la luz de la Verdad; el que se desengañó y se le abrieron los ojos para salir de la ignorancia original y despertar a la Verdad última. Su nombre completo: Siddharta Gautama Shakamuni. Siddharta, el nombre y Gautama, el apellido. Shakamuni: un sabio (muni) del clan de los shakyas. Bienaventurado o Reverendo (sk. bhagavat) es el tratamiento respetuoso por parte del discipulado. Con la figura histórico-legendaria de Gautama, el Buda, comienza la tradición del budismo entre los siglos VI y V antes de nuestra era. ¿Es el budismo religión, filosofía o ética? Es camino de espiritualidad, al que despertó el Buda y ayudó a que otras personas despertasen. Le preceden unas tradiciones indias de entrenamiento ascético corpóreo-espiritual. Visto desde esas tradiciones, el nuevo movimiento tenía que parecer reformador. Al negar autoridad a los Vedas tradicionales, chocaba con la ortodoxia de los brahmanes indios. Shakamuni se desengañó ante la esterilidad de las discusiones; el ejemplo típico, la atención al herido por una flecha. "No discutamos sobre quién disparó. Urge curarlo".

\footnotetext{
${ }^{11}$ Loto, cap. 16, pp. 280-281.

${ }^{12}$ Gautama se hizo uno con esta realidad última del Dharma. Por eso un texto citado con frecuencia refiere que en cierta occasion el Buda dijo a sus discípuls algo que recuerda el dicho de Jesús a sus seguidores: "Quien me ve a mí, está viendo al Dharma”. Encontrarse con el Buda era encontrarse y ser introducido en la realidad y la fuerza del Dharma. KNITTER, Paul F. Without Buddha I Could not be a Christian. Oxford: One world, 2009, p. 112.
} 
El noble Gautama tiene cuanto quiere, pero vive en un invernadero. Un día sale fuera de palacio y se le abren los ojos. Es el primero de tres cambios de ruta en su vida. Choque fuerte, el encuentro con el sufrimiento: un anciano decrépito, un enfermo, un cadáver que llevan a enterrar y un asceta peregrino. Surge el primer giro decisivo en su vida. Abandona familia y comienza ascesis, primera conversión. Comienza vida mendicante y medita sobre fugacidad de la vida.

Pero también por este camino hay extravíos. Aunque había pasado del palacio a la ascesis, no halla lo que busca. ¿De qué sirve pasar de un extremo al otro? Entonces descubre la vía media, un nuevo cambio de ruta: segunda conversión. Cambia de estilo de vida: se asea, come con moderación y entra por una vía media (no un punto intermedio inmóvil, sino un camino; no una tercera, sino una cuarta vía como la del "óctuple sendero" en el sermón de las cuatro verdades...); ni excesiva comodidad, ni demasiada ascesis. Meditando una noche sobre el enigma del sufrimiento, halla la paz del nirvana, después de haber salido victorioso de su confrontación con el mal, personificado en la figura de Mara, el tentador, que le acosaba durante la meditación. Encuentra la paz, y "se despierta", se desengaña, es iluminado.

Tercera conversión: Shakamuni descubre que la paz de la contemplación no debe disfrutarla solo. Llamado a transmitir el camino descubierto, comienza a predicar y gana discípulos. La paz del nirvana no debe disfrutarse a solas; ayudemos a que otros lo descubran. Sirviéndose de lo aprendido por experiencia personal, va a comunicar a otros la enseñanza, la verdad del dharma: la hondura de la realidad.

En estos tres cambios de ruta se resume la trayectoria de Shakamuni para entrar por el camino de la iluminación y compasión: el paso de la ilusión a la ascesis (desengaño), de la ascesis a la lucidez de la vía media, y de la sabiduría iluminada a la lucidez compasiva. Desengaño lúcido y compasión cordial. Shakamuni, el Buda, predicó esta verdad de diversas maneras, unas más asequibles, como el sermón de las cuatro verdades sublimes; otras, más complicadas, como la causalidad, interconexión y relación de todo con todo.

Tras esta exposición sencilla por parte de la comunidad DB, representantes de la comunidad DJ, preguntan: ¿Qué es el Dharma?

El Dharma, responde DB, es la expresión de la verdad que iluminó al Buda Shakamuni. Vida inmensa, sin forma, más allá de espacio y tiempo, vivificador incesante de todo. La fe percibe su presencia en todo. Observo una hierbecita entre las grietas del pavimento: ¿De dónde le vendrá la fuerza para 
abrirse paso entre el asfalto? El maestro Saigyo (1118-1190) versificó: "Palpo aquí una presencia latente / No sé quién es. / Pero brotan lágrimas de agradecimiento". Esta experiencia se expresa orando. El Dharma es Verdad de Vida ilimitada, que trasciende y llena todo. Se abrieron los ojos de Gautama ante el sufrimiento y buscó la liberacion de la ceguera original. Lo expresó predicando las "cuatro verdades sublimes" y los "doce eslabones de la cadena causal". En resumen: la insustancialidad -nada existe con individualidad independiente-, y la fugacidad -nada inmutable- y la interconexion -todo relacionado con todo-, lo eterno, que hace cambiar todo, es una realidad última que se nos escapa al tratar de conceptualizarla, sugerida en la nocion de Dharma: Verdad última y Vida verdadera.

La comunidad DJ puede sintonizar con este testimonio de fe de la comunidad DB. Y preguntan cómo encontrar al Buda, cómo vivir esta espiritualidad. Responden desde DB:

El misterio llamado Buda, Dios o lo Sagrado está en nuestro interior. Montes y ríos, valles y arroyos, todo es cuerpo de Buda, manifestación de su vida. ¿Lo llamaremos Buda, Dios, o Allah? El nombre no importa. A Shakamuni le preocupaba librarse del sufrimiento original: vivir, envejecer, enfermar y morir. Liberado de la oscuridad radical, descubre la relacion de todo con todo y la necesidad de desatarse del deseo desorientado. Usó "recursos" para transmitirlo. Hasta nuestra manera de hablar de Buda empobrece su realidad. Por eso el Buda usa parábolas y "recursos salvíficos" o maneras de exponer la doctrina, hablando a cada persona según pueda entender. Cualquier expresión de lo sagrado irá acompañada de negación. Hay que vaciarse del apego a sí mismo y a las imágenes con que nos referimos al Dharma. Consciente de la relatividad de todo, Shakamuni siente la necesidad de vaciarse y liberarse, de evitar convertir en absoluto lo que no lo es, comenzando por uno mismo. Pero esta Nada o Vacio budista no debe entenderse como nihilismo, ni como un ascetismo mortificador. Tampoco es una negación de la Realidad última. Shakamuni no la negaba, aunque guardaba silencio ante las preguntas metafísicas".

Hasta aquí la comunidad DB. Sintoniza con ella la comunidad DJ. Pero otros, desde la teología o la budología, pondrán objeciones. ¿Darían otra explicación diferente en otras corrientes budistas?

Efectivamente, responden desde DB, en este punto contrasta la escuela Mahayana y la corriente tradicional del budismo primitivo Theravada. El 
budismo Mahayana insiste en la misericordia del Buda eterno y el camino de la compasión del bodisatva, que vive para los demás. El budismo Theravada acentúa la figura del arahat que, mediante el desapego, se libera del sufrimiento y de la cadena del renacer. Pero, incluso en el budismo Theravada, hubo algo semejante a la figura del bodisatva, que no se contenta con su propia salvación, sino vive para la salvación de los demás.

Le hacen entonces una pregunta personal al representante de DB, En el caso de usted, ¿se dirige su fe al Buda histórico Shakamuni o al que ustedes, en la tradición Mahayana, llaman el Buda cósmico eterno? A lo que responde testimonialmente:

Mi fe budista me hace hallar en todas las cosas al Buda eterno, una de cuyas manifestaciones históricas es el Buda Shakamuni. En el budismo Mahayana, la escuela de Yogâchâra (s.IV-V) habla de la sima de la conciencia, de donde brota el mal original. Pero hay un nivel más profundo, la bondad original: es lo que se llama la naturaleza búdica o iluminabilidad en nuestro interior, que nos capacita para la iluminación. Percatarse de ello es ser iluminado, lo que se llama en los sutras "encender la luz del Dharma". ${ }^{13}$

En el sabio del clan de los Shaka, el Shakamuni (Shakyamuni en sánscrito; Shakamuni en japonés y español), se manifestó, como en otros Budas o iluminados, el secreto del Buda eterno, símbolo de la Vida que sostiene y envuelve todo, que existe desde siempre y para siempre. Discuten los lingüistas si su nombre debe traducirse literalmente como «el Así-ido» o «el Así-venido». En realidad, es el «Así-Siempre-Presente». En japonés, Nyorai, el que viene de la luz y de la realidad; en sánscrito, Tathâgata, el «así tal cual», al que la devoción popular llamará el Bhagavat o Bienaventurado, el Reverenciado en todo el mundo.

Con el fin de salvarlos a todos/me manifiesto como extinguido,/cual recurso de salvación./ Pero, en realidad, no me extingo: permanezco. No estoy en la otra orilla, sino aquí, /entre vosotros, anunciando/ día a día el mensaje del Dharma. ${ }^{14}$

\footnotetext{
${ }^{13}$ SUZUKI, Kotarö. "El Buda histórico y el Buda eterno”. En: MONCLÚS, A. (Eed). Teologías en entredicho. Campo de Gibraltar: Universidad internacional Menéndez Pelayo, 2012, p. 67.

${ }^{14}$ Loto, cap. 16, p. 279.
} 
Cuando el equipo de traducción al español del Sutra del Loto debatía sobre el significado de Nyorai (en japonés), con los dos caracteres chinojaponeses de "realidad" y "venir", porque viene de la verdadera realidad (shin-nyo), preguntamos al Dr. Kotaró Suzuki su opinión. ¿Cómo traducir el epíteto del Buda: Tathâgata? ¿Debemos decir que el "Así tal cual” es, como dicen versiones inglesas el "Así ido" o, según otra posibilidad gramatical, el "Así venido o llegado"? Nos responde el especialista, buen conocedor del Loto: "Literalmente lo mismo se podría decir "ido" que "llegado", pero ambas expresiones son inexactas. En realidad está ya viniendo siempre en cada momento, es eternidad en el presente". El traductor familiarizado con el evangelio evoca inmediatamente el prólogo del evangelio de san Juan, que dice sobre la Sabiduría de la Palabra Encarnada: "Ella era la luz verdadera, ilumina a todo humano y estaba siempre llegando a este mundo" (Jn 1, 9). A partir de ese momento, el equipo de traductores decidió arriesgarse a usar en la traducción al español el Así-Siempre-Presente como versión del epíteto Tathâgata para el Buda Eterno, no solo en el capítulo 16, sino en toda la obra.

\section{El Camino de la práctica compasiva de los bodisatvas}

El Camino de los bodisatvas conduce hacia la ruptura de las cadenas de violencia en este "mundo de pesares", mediante la compasión y benevolencia que renuncian a la agresividad (en japones, jihi; en sánscrito, karuna: benevolencia, y maitri: no agresividad).

La enseñanza del Buda no es exclusivamente para un grupo selecto de monjes, sino para todo el mundo. No está en libros o templos, sino en la práctica. Y la práctica es el camino del bodisatva: alguien en camino hacia la Iluminación perfecta, hasta convertirse en un Buda; pero el bodisatva retrasa su logro del nirvana para permanecer dedicado a vivir para la salvación de todo el mundo por el camino de la compasión: maitri y karuna en sánscrito, jihi en japonés.

Lucidez y compasión son dos palabras clave a lo largo de este sutra. La figura de la «persona en camino de la iluminación» (en sánscrito, bodhisattva; castellanizado, bodisatva), en las corrientes budistas llamadas del Gran Vehículo (Mahayana) encarna las dos actitudes fundamentales resumidas en estas dos palabras clave. El bodisatva halla la lucidez practicando la meditación y avanza por el camino enseñado por el Buda, realizando la compasión; aspira a alcanzar la budeidad o lucidez de la iluminación, pero renuncia a entrar 
en el nirvana definitivamente, con el fin de dedicarse compasivamente a la liberación de los demás vivientes.

El bodisatva tiene una experiencia espiritual que es, ante todo, de lucidez agradecida; pero no la guarda para sí, sino que se siente responsable de cooperar, mediante la práctica de la compasión, a fin de que se extienda ampliamente el ámbito de esa iluminación. La meta final es que todos los seres humanos se conviertan en Budas, descubriendo que ya lo son, gracias a la presencia en todo de la naturaleza búdica, luz que todo lo ilumina y vida que todo lo vivifica.

Entre los bodisatvas de los capítulos 17 al 28 del Loto, destacan especialmente las figuras del bodisatva Jamás Menosprecia (cap. 20), que resulta fundamental para comprender la enseñanza sobre el sentido del perdón, y la del bodisatva Acogedor del Mundo (cap. 25), que «escucha con sus ojos y ve con sus oídos» los sufrimientos de todos los seres y extiende sus manos misericordiosas para auxiliar y salvar al mundo entero. ${ }^{15}$

...En aquellos días,/la cuádruple asamblea especulaba/ con apegos sobre el Dharma./ El bodisatva Jamás Menosprecia/ se les acercaba y decía:/ No os menosprecio,/ vosotros practicáis el Dharma,/estáis llamados a ser Budas... ${ }^{16}$

\section{Hacia el "Otro Oriente", con el Buda y con Jesús}

Cuando la comunidad DJ, al compartir espiritualidad con DB, se deja guiar por la "escucha budista de la voz del Dharma", puede redescubrir la riqueza de lo que significa para una conciencia cristiana "respirar en el Espíritu de Vida". A su vez, la fe budista puede experimentar una transformación semejante. Se conoce mejor la propia lengua, al mismo tiempo que se la relativiza, al estudiar una lengua extranjera. Algo semejante acontece en el intercambio de espiritualidades. Esto no quiere

\footnotetext{
${ }^{15}$ Este último es el bodisatva Kanzeon (o Kannon), prototipo que personifica este estilo de vida (cap. 25). «Kanzeon» es un compuesto de tres caracteres: Kan (mirar), $\mathrm{Ze}$ (el mundo), On (sonido). La representación icónica ha recurrido a figuras con infinidad de ojos y oídos para ver y escuchar el clamor de todas las personas angustiadas, además de infinidad de manos para atender toda necesidad. Tras la época de persecuciones, los cristianos japoneses que mantenían su fe ocultamente utilizaron estatuillas de Kannon como imágenes de la Virgen, con el nombre de «María Kannon, madre de misericordia».
}

${ }^{16}$ El Sutra del Loto, p. 318. 
decir que sea recomendable la mezcla sincretísta de religiosidades. En los encuentros que han servido de base para estas reflexiones nadie pretendía convertir a budistas al cristianismo, ni tampoco convertir a cristianos en budistas. Lo cierto es que, en el encuentro auténtico de espiritualidades, ambas partes redescubren la propia identidad, a la vez que se transforman mutuamente. Ambas partes salen del encuentro siendo "más y menos budista o más y menos cristiano que antes". Es una paradoja de la que se puede testimoniar si se ha vivido encuentros semejantes. Si llamamos al Absoluto " $X$ ", diremos que "X" está más allá de las imágenes que budistas y cristianos tienen de Buda o de Cristo. El auténtico diálogo conduce hacia más allá de la sola conversación, hacia la transformación mutua.

Cuando hacemos estas reflexiones no podemos olvidar que la religiosidad y espiritualidad son inseparables de sus expresiones en la cultura y el lenguaje. Si el cristianismo se hubiese extendido hacia el Este por India y China, en vez de hacia el Oeste por Grecia y Roma, quizás no tendríamos hoy unas formulaciones trinitarias tan complicadas como las de Nicea y Calcedonia, pero tendríamos tal vez otras tan complicadas como las especulaciones del Abidharma y las posteriores elucubraciones budistas sobre los tres cuerpos del Buda. También es cierto que, en la tradición budista se produjo la reacción mística de los Sutras de la Sabiduría como contrapeso a los excesos especulativos anteriores. Y también hay una tradición mística en Occidente, aunque ha quedado a menudo marginalizada frente a la corriente central de teologías dogmáticas y sistemáticas, que temían a los iluminismos y sospechaban de cualquier relativización. En todo caso, unos y otros necesitan hoy influenciarse mutuamente para redescubrir las raíces de una espiritualidad que vaya, más allá de orientalismos superficiales, hacia esa hondura de la vida que podríamos llamar el "Otro Oriente". No el Oriente geográfico, ni el Oriente exótico o contrastante con lo "occidental", sino el Oriente profundo en el fondo de los orientes y occidentes superficiales.

En ese Oriente profundo el Dios Abba de Jesús y el Buda Eterno Originario están mucho más cercanos de lo que creemos. Ni el primero representa un teismo antropomórfico en las alturas, ni el segundo un monismo impersonal difuminado por la superficie de la esfera. Ambos se encontrarían más bien en el centro de la esfera. Y desde allí hasta cualquier punto de encarnación en la superficie la distancia será la misma.

Desde esta manera de entender la espiritualidad oriental (del "otro 
Oriente") ya no diremos que el mensaje de Shakamuni es oriental y el de Jesús occidental. Ambos representarían la voz del Oriente profundo. Lo vemos expresado en la imagen de Jesús en el monte Tabor y la de Shakamuni en el monte Cresta del Águila, en el Sutra del Loto. El monte Tabor no es el monte Sinaí, de rayos y truenos. El monte de Cresta del Águila no es el monte Sumeru, de las cosmologías de China e India, también con sus equivalentes rayos y truenos. El Jesús del monte Tabor expresa la iluminación y transfiguración de la vida cotidiana. Después desciende del monte para hacer bien, curar y ayudar a las personas. El Shakamuni del monte de Cresta del Äguila desprende una luz de vida que transforma este mundo y envía a los bodisatvas a hacer el bien y practicar la compasión. Por eso no podemos ver el monte Sumero de India y China como representación exclusiva de lo oriental y el monte Sinaí como la de los presuntos monoteísmos exclusivistas occidentales. Ambos coinciden en tener algo del ambiente de rayos y truenos desde las alturas cayendo sobre la superficie de la vida. En cambio, el monte de Cresta del Águila, del sermón de Shakamuni, y el monte Tabor, de la transfiguración de Jesús, son ambos fuente de luz y calor desde las honduras de la vida para iluminar la cotidianidad. Ambos son lugares del "Dios del Oriente profundo". El mensaje de Jesús en el Tabor o el de Shakamuni en Cresta de Águila, invitan, además, a caminar para ponerlo en práctica. Como Pedro, Santiago y Juan, en el monte de la Transfiguración, o Kashapa y Sariputra en el monte de Cresta de Águila, una palabra de luz y vida envía a los discípulos a iluminar y dar vida en la cotidianidad. Los budistas llaman "mundo de pesares" (saha, en sánskrito) a esta realidad cotidiana que la fe medieval llamó "valle de lágrimas". Ahí es donde budistas y cristianos han de comprometerse para enjugarlas, fomentando juntos en todas partes procesos de paz y culturas de vida.

Así y todo, hemos de reconocer honestamente que, a diferencia de los encuentros de espiritualidad como los referidos en estas páginas, en los diálogos interreligiosos de budología y cristología sigue siendo controvertida la cuestión sobre el Dios personal. No era el tema de estas páginas. Me limito a constatarlo aquí como cuestión pendiente para continuar el diálogo interreligioso a nivel de investigación de budología y cristología. 


\section{Referencias bibliográficas}

ALONSO SCHÖKEL, L. (Trad.). La Biblia de nuestro pueblo: La Biblia del Peregrino. Bilbao: Sal Terrae-Mensajero, 2011.

KNITTER, Paul F. Without Buddha I Could not be a Christian. Oxford: One world, 2009.

MATEOS, J.; ALONSO SCHÒKEL, L. (Trad). Nuevo Testamento. Madrid: Cristiandad, 1987.

MASIÁ CLAVEL, Juan (Ed. y Trad.). El Sutra del Loto. Salamanca: Ed. Sígueme, 2009.

MASIÁ CLAVEL, J.; SUZUKI, K. O Dharma e o Spirito. Coimbra: Ed. Angelus Novus, 2009.

SUZUKI, Kotarö. "El Buda histórico y el Buda eterno". En: MONCLÚS, A. (Ed.). Teologías en entredicho. Campo de Gibraltar: Universidad internacional Menéndez Pelayo, 2012.

Juan Masiá Clavel SJ

Doctor en Filosofía

Profesor de Ética cristiana

Facultad de Teología

Universidad Sophia

Tokyo

E-mail: masiaster@gmail.com

Recebido em: 28/12/2016

Aprovado em: 03/02/2017 